\title{
A message from magic to science: seeing how the brain can be tricked may strengthen our thinking
}

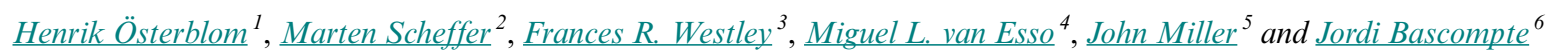

\begin{abstract}
Scientific discoveries rely on creative thinking, and several authors have explored similarities in and differences between creativity in the sciences and that in the arts. Here we explore possible ways in which science can learn from the arts, focusing specifically on experiences derived from the art of magic and on the limitations of human cognition. Generations of stage magicians or "illusionists" have made sophisticated use of the weaknesses in human systems of perception and interpretation. We highlight three important principles of magic tricks, including: (1) the audience see what it expects, (2) it is blind to all but the focus of attention, and (3) ideas spring predictably from a primed mind. These principles highlight a number of important tendencies, which we argue are shortcomings in the ability of scientists to perceive the world, and which scientists need to be aware of. Consciously addressing these shortcomings may help scientists improve their creativity, and will strengthen their capacity to address complex and global challenges.
\end{abstract}

Key Words: art; cognitive capacity; cognitive limitations; conclusion errors; confirmation bias; creative thinking; illusion; illusionist; inattentive blindness; magic; magician; priming; science; scientific discovery; selective attention

\section{INTRODUCTION}

Human beings evolved under very different conditions than those of today: in the Stone Age the brain was hardwired for survival. Humans have made the most out of these evolutionary constraints, resulting in an overwhelmingly rich set of scientific and technological achievements, but to ignore the fact that these achievements are structured by cognitive capacities is likely to result in both type 1 and type 2 errors: humans are convinced of the truth of what they see, even though the brain is geared to selective attention. Humans also fail to identify phenomena that exist, but which cognitive capacities make them likely to ignore.

For more than 150 years, since the widespread use and application of scientific methodologies, there has been a debate about the similarities and differences between art and science. Significant thinkers on both sides of the divide have struggled with the tendency to divide knowledge into rational scientific approaches or the more interpretive approaches of the humanities. C. P. Snow, in his influential book The Two Cultures (1959), viewed this division as a major impediment to solving world problems, a concern echoed in E. O. Wilson's Consilience (1998) and Stephen Jay Gould's Crossing Over-Where Art and Science Meet (2000). A. Koestler in turn has proposed a general theory describing the interactions between art and science in human creativity (Koestler 1964). All these writers treat the division between art and science as a false dichotomy and argue, that in an increasingly complex world, the challenges cannot be addressed without a better synthesis.

Often when artists and scientists have worked together, they have done so sequentially: scientists employ artists as illustrators and communicators for scientific thinking - in so doing, hoping to reach a wider audience and to stimulate an emotional response to such emerging issues as climate change. Consistent with earlier thinking about how the brain worked, this kind of collaboration echoes ideas about the bicameral mind - the right brain is used for more intuitive (i.e., artistic) thinking, the left brain is used for more rational (i.e., scientific) thinking, and hence a division of labor occurs between scientific problem solving and the engagement of emotions (Jaynes 1976). Although its now known that this model oversimplifies the division of brain activity, different regions of the brain do specialize in specific thinking processes with ties to sensory organs. However, in recent years there has been extensive research on the nature and limitations of cognition. Not surprisingly, in economics, once a science dominated by the idea of rationally operating humans, the limitations of rationality have received much attention. The Nobel Prize in Economics was awarded to psychologist Daniel Kahneman for his work showing the limited role of rationality in decision-making. Similarly, the concept of bounded rationality, proposed by psychologist Herbert Simon as a way of describing the limited capacity of humans to use information, has been influential (Simon 1977). More broadly, there is now an extensive branch of psychology dealing with the limitations of attention. However, undeniably the human mind has some well-documented fundamental limitations, which are all too easily overlooked.

Can an exploration of the arts add further nuance to the study of these limitations? We believe so. In particular, this essay looks at the relationship between the art of magic and the limitations of human cognition, with special reference to scientific research. Long before psychologists studied such limitations of the brain, generations of stage magicians, or illusionists, already made sophisticated use of the weaknesses in the human systems of perception and interpretation. For centuries, audiences have marveled at the art of magicians in places ranging from palaces to marketplaces (Fig. 1). In a sense, these illusionists were specialized psychologists avant-la-lettre, and somehow their work reveals the mental limitations of humans in ways that are more striking than has been described in many modern scientific publications. In this essay, we do not dig deeply into the scientific literature on attention and cognition. Instead, we highlight three important principles of magic tricks: the audience see what it expects, it is blind to all but the focus of attention (Macknick and Martinez-Conde 2011), and ideas spring predictably from a primed mind.

${ }^{1}$ Stockholm Resilience Centre, Stockholm University, ${ }^{2}$ Aquatic Ecology and Water Quality Management, Wageningen University, ${ }^{3}$ Waterloo Institute for Social Innovation and Resilience, University of Waterloo, ${ }^{4}$ College of Agriculture, Buenos Aires University, ${ }^{5}$ Gray Jay Graphics, Wisconsin, ${ }^{6}$ Institute of Evolutionary Biology and Environmental Studies, University of Zurich 
Fig. 1. An illusionist at work in the painting The Conjurer, created by the Flemish painter Hieronymus Bosch in about 1502. [Photo from http://en.wikipedia.org/wiki/The Conjurer (painting)]

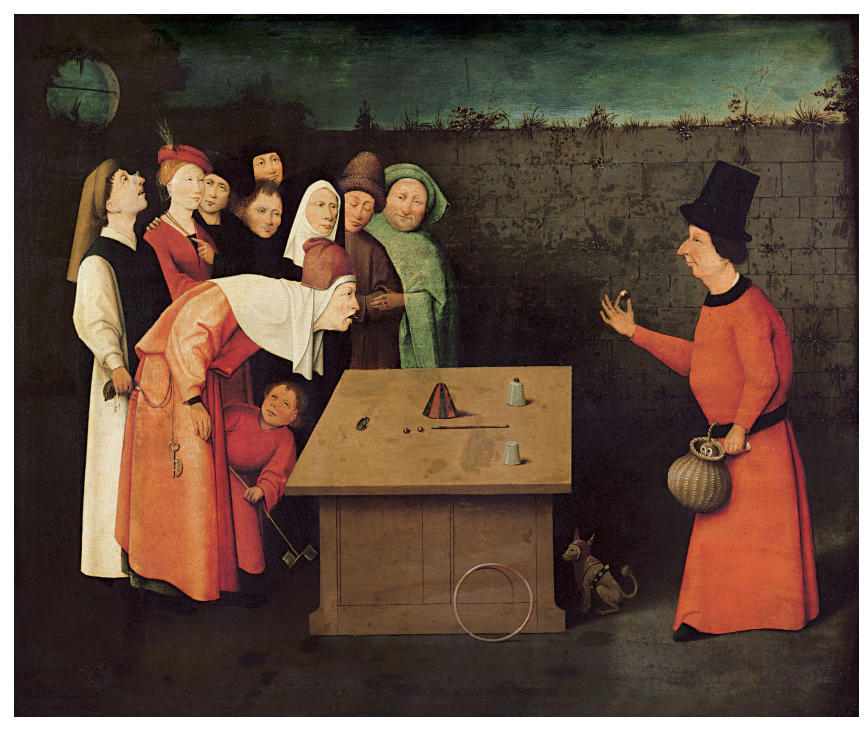

\section{WE SEE WHAT WE EXPECT}

The vanishing ball is a well-known magic trick illustrating how strongly observation is shaped by past experience. A ball apparently disappears in mid-air. A magician, who first throws a ball repeatedly into the air while following it with his gaze and then capturing it again, achieves this illusion. When, subsequently, he makes the same movements but secretly keeps the ball in the palm of his hand, the majority of the observers strongly perceive the ball leaving his hand upward and then vanishing in the air (Kuhn and Land 2006).

The tendency of scientists to see what they want to see implies problems for scientific practice, which have been long known. In fact, the warning of Spinoza against the dangers of dogma could be seen as addressing the same issue. In psychological literature the problem is known as confirmation bias (Nickerson 1998), and it is perhaps the best-known error in reasoning. In science it is arguably one of the forces that make it difficult to abandon a theory. One simply tends to see evidence that confirms a theory more easily than one sees observations that, from the point of view of the theory, are "unexpected". Clearly this tends to lead to more inertia than would be warranted in view of (what in retrospective often may be referred to as) objective facts. This tendency tends to play out strongly in the individual mind, but a similar tunnel vision can scale up, enforced by social feedbacks, to keep an entire field of science captivated by one particular look at the world.

For example, in his classic work Kuhn (1962) argues that the history of science is one of breakthroughs followed by many years of "normal science" which "does not aim at novelties of fact or theory and, when successful, finds none". This is the period of seeing what one expects. Eventually, however, scientists with a less orthodox turn of mind begin to notice what they do not expect
- what Kuhn calls anomalies. There will often be attempts to introduce new ways of seeing, new theories that are rejected by orthodoxy, but eventually a breakthrough is made. Those who found new "paradigms", such as Darwin and Einstein, tend to become the heroes of the history of science. Studies of Nobel Prize and MacArthur Genius award winners suggest that their early experiences and those of artists, were very similar: both engage in using the imagination to give substance to the "unseen", both often engage in serious "world play", and both create imaginary worlds (Root-Bernstein and Root-Bernstein 2006). In effect, the bedrock of creativity, among both artists and scientists, is the questioning and challenging of perceived reality and received wisdom. Unfortunately, "normal"science is more geared to building on what is already known, and much less on discovering "what we don't know we don't know" (Luft 1969). Magic on the other hand, is an art form built on an acute awareness of what the audience doesn't know it doesn't know.

\section{WE ARE BLIND TO ALL BUT THE FOCUS OF OUR ATTENTION}

One of the limitations of the human mind that is extensively used by magicians is the fact that humans can really only pay attention to one thing at a time. If a magician suddenly produces a flying dove, the bird will capture the audience's attention, allowing a moment for an unnoticed simultaneous maneuver. A stunning illustration of the magician's ability to drive the attention of the audience, and therefore blind it to anything else, is the use of movement and visual contact. Indeed, there are two powerful ways to drive the attention towards one hand. One way is by moving one hand, while the other hand (the one the magician wants to audience to be blinded of) remains still. The audience's perception reacts to the moving hand, not the still one. The other way is by looking directly at the moving hand. The combination of the two strategies is very powerful and almost everyone will focus their attention to the moving hand.

In cognitive psychology the inability to see something other than the topic of attention is known as inattentional blindness. It falls more broadly into the work revealing the limitations of the human mind when it comes to its capacity for attention (a simple Wikipedia search for the keyword "attention" will provide many pointers to this wide field). However, unlike the effects of confirmation bias, the implications of the focus blinding effect for the process of scientific inquiry have not been discussed widely to our knowledge. Yet, one could speculate that the blinding effects of focus might well be one of the main limitations when it comes to unraveling the working of complex systems. Science is sometimes depicted as producing islands of insight in a sea of ignorance. While focus allows scientists to single out well-defined problems and resolve them with scientific accuracy, the same power of focus might well prevent them from noticing the sea of ignorance.

Examples are replete. Consider the sometimes blinding focus on sustainable fisheries. Lobster fisheries in Maine have flourished thanks to well-established and enforced social norms and are regarded an example of success in overfishing prevention (Steneck et al. 2011). However, the success has blinded local communities and scientists alike to the fact that the lobster fisheries have turned into a monoculture, at risk of collapsing when disease strikes as a consequence of increasing vulnerabilities and climate change 
(Steneck et al. 2011). On a larger scale, environmental problem shifting is well known. For example, local successes in controlling deforestation or overfishing are often celebrated; a broader system perspective reveals that a decrease in resource exploitation in one country or region is offset by an increase in resource extraction in adjacent countries or regions (Österblom et al. 2010, Meyfroidt et al. 2013).

\section{IDEAS SPRING PREDICTABLY FROM A PRIMED MIND}

On the positive side, the human mind has a remarkable capacity to come up with new ideas. Such generation of novelty depends to a great extent on the capacity to make novel associations; the so-called "fast thinking" part of cognition (Kahneman 2011). The "associative machine" can connect the many things that scientists have in mind (consciously or unconsciously), to produce new ideas or insights. Obviously, such connections can only be made between the elements we have at hand, making this machinery entirely dependent on the collection of elements that have entered the mind. Illusionists can use this dependency to create the illusion that they read your mind, or indeed "foresee" what you are going to think. The way it works is that the illusionist primes the unconscious minds of the audience with elements, and subsequently asks the audience to take something in mind or produce some idea quickly. As the priming makes certain outcomes highly likely, they can foresee those. (For an example see https://www.youtube.com/watch?v=ZyQjr1YL0zg.)

Here the use of magic reveals that what could be a weakness could also be a strength. Clearly, seeding the mind with elements is essential for scientific progress. A massive study of scientific articles just showed that the highest impacts often come from studies that contain an atypical link to a very different field of science (Uzzi et al. 2013). This raises the question as to why such influential links are so unusual. Clearly, if the associative machine of the brain is fed with more of the same, not much novel connection may be expected. By contrast, if unbridled curiosity guides scientists on a random walk collecting a wildly diverse set of elements for the associative machine, there is a great potential for novelty to be generated by associations. As Nobel laureate Kenneth Arrow characterized his attitude in a conversation with one of us (MS): "It is so far from anything I do, I must be interested." The possibility that having such a broad interest helps scientists to be innovative is well in line with the fact that winners of prestigious science prizes such as the Nobel Prize without exception seem to have internalized a great deal of scientific diversity (Whitfield 2008).

Nassim Nicholas Taleb (2007) writes about the human tendency to seek simple explanations for outlier events in his book The Black Swan: The Impact of the Highly Improbable. The limits of the human brain are obvious, and the challenges are made even greater when the brain must deal with new information that it cannot easily evaluate within the context of the known. Expertise confined to one subject area can therefore impose limits on problem-solving abilities and/or on the appreciation of the possibilities of new information and how to evaluate it. One thinks about the new within the context of the known, a weakness of inductive reasoning. It seems logical that the broader one's knowledge, the less prone an individual might be to reasoning error since the new would be analyzed within a more vast body of known possibilities. It is potentially for this reason that magicians have a golden rule: never repeat the same magic trick with the same audience. With sufficient intent, the plasticity of the brain allows for "double-loop learning" (Argyris and Schön 1974), i .e., learning that allows the learner to discern the rules structuring the ideas or the communications as opposed to simply internalizing these. The equivalent in magic would be to discern the rules and routines that create the illusion, as opposed to focusing on the illusion itself. Presumable repeat performances of a single trick makes such double-loop learning more likely.

\section{CONCLUSION}

We do not want to suggest that illusionists can teach scientists more about the limitations of the mind than modern cognitive psychology. However, the surprising power of illusionist's tricks is undeniable. As an art form, it has the power to astonish and confound us, and induce a kind of uncertainty and confusion which is a necessary precursor to reassessment and to creativity (Van Eenwyk 1997). Few college courses in science focus on "unknowing"; most are focused on mastering of the known (although, for instance, quantum physics illustrates uncertainties in "the known", c.f. Merali 2015). The art of magic may be used as a powerful experiential reminder of the weaknesses of humans' cognitive abilities. Science, if it is to remain a true exploration, must actively address those weaknesses. It is therefore important to remain alert to the omnipresent effects of confirmation bias, inattentive blindness, and priming, which are illustrated so vividly by many magic tricks. Including video examples of magic in classes on scientific methods may provide eye-openers that stick in the minds of students long after they leave university. Magic is also a pointer to the value of the "artistic eye" that welcomes uncertainty and searches for novelty, not familiarity, at the early stages of scientific breakthrough.

Although magic will not help scientists guard against conclusion errors, it serves as a clear reminder of the human tendency to reach false and/or limited conclusions. Readily accepting the attitude "I might be wrong" can be a time saver given the human tendency to cling to perceived "observable fact". For this reason alone, using examples of performance magic in the classroom could reinforce commitment to the disciplined processes of scientific research. There are at least two additional reasons to use examples of magic in the classroom. First, it may also serve the purpose of teaching students to be critical of the flow of information in the media: things are oftentimes not as presented. Second, it provides an inspirational effect when it comes to the marvels of the discovery process itself. Magic is an art. Clearly the art of magic anticipated, practiced, and codified qualities of the limited brain hundreds of years before science delved into explanations. Art allows humans to explore the world in ways that are frequently guided by feelings of wonder; it seeks understanding, and packages the found "knowledge" on its own terms. Art and science do not differ in this regard. The excellent scientist should be prepared to be comfortable with the methods and perspectives of "normal" science, as well as those of the creative iconoclast. Creating scientific spaces for creativity, where paradigms and perceived realities can be explored, will help in unraveling future scientific insights of illusions that are currently perceived as realities. Remember, magic strengthens the inner iconoclast. 
Responses to this article can be read online at: http://www.ecologyandsociety.org/issues/responses. $\mathrm{php} / 7943$

\section{Acknowledgments:}

This work originates from discussions during the 2013 and 2014 annual meetings of SARAS (South American Institute for Resilience and Sustainability Studies) in Maldonado, Uruguay. $H$. Österblom was supported by BEAM (Baltic Ecosystem Adaptive Management) and Mistra, through a core grant to the Stockholm Resilience Centre. M. Van Esso acknowledges travel support from SARAS. J. Miller participated as a member of the Yahara 2070: Water Sustainability and Climate in the Yahara Watershed, University of Wisconsin-Madison. H. Österblom and M. Scheffer contributed equally to leading the paper, which was based on an original idea by J. Bascompte and M. Scheffer. All authors contributed to the writing of the paper.

\section{LITERATURE CITED}

Argyris, C., and D. A. Schön. 1974. Theory in practice: increasing professional effectiveness. Jossey-Bass, San Francisco, California, USA.

Gould, S. J. 2000. Crossing over: where art and science meet. Three Rivers Press, New York, New York, USA.

Jaynes, J. 1976. The origin of consciousness in the break-down of the bicameralmind. Houghton Mifflin Company, Boston and New York, USA.

Kahneman, D. 2011. Thinking, fast and slow. Farrar, Straus and Giroux, New York, New York, USA.

Koestler, A. 1964. The act of creation. London, UK.

Kuhn, G., and M. F. Land. 2006. There's more to magic than meets the eye. Current Biology 16:R950-R951. http://dx.doi. org/10.1016/j.cub.2006.10.012

Kuhn, T. S. 1962. The structure of scientific revolutions. University of Chicago Press, Chicago, USA.

Luft, J. 1969. Of human interaction. National Press, Palo Alto, California, USA.

Macknick, S. L., and S. Martinez-Conde. 2011. Sleights of mind: what the neuroscience of magic reveals about our everyday deceptions. Henry Holtl and Company, LLC, New York, New York, USA.

Merali, Z. 2015. Quantum physics: what is really real? A wave of experiments is probing the root of quantum weirdness. Nature 521:278-280. http://dx.doi.org/10.1038/521278a

Meyfroidt, P., E. F. Lambin, K.-H. Erb, and T. W. Hertel. 2013. Globalization of land use: distant drivers of land change and geographic displacement of land use. Current Opinion in Environmental Sustainability 5:438-444. http://dx.doi.org/10.1016/ j.cosust.2013.04.003

Nickerson, R. S. 1998. Confirmation bias: a ubiquitous phenomenon in many guises. Review of General Psychology 2:175-220. http://dx.doi.org/10.1037/1089-2680.2.2.175
Österblom, H., U. R. Sumaila, Ö. Bodin, J. Hentati Sundberg, and A. J. Press. 2010. Adapting to regional enforcement: fishing down the governance index. PLOS ONE 5:e12832. http://dx.doi. org/10.1371/journal.pone.0012832

Root-Bernstein, M., and R. Root-Bernstein. 2006. Imaginary worldplay in childhood and maturity and its impact on adult creativity. Creativity Research Journal 18:405-425. http://dx.doi. org/10.1207/s15326934cri1804 1

Simon, H. A. 1977. Models of bounded rationality, volume 3: empirically grounded economic reason. The MIT Press, Cambridge, Massachusetts, USA.

Snow, C. P. 1959. The two cultures. Cambridge University Press, New York, USA.

Steneck, R. S., T. P. Hughes, J. E. Cinner, W. N. Adger, S. N. Arnold, F. Berkes, S. A. Boudreau, K. Brown, C. Folke, L. Gunderson, P. Olsson, M. Scheffer, E. Stephenson, B. Walker, J. Wilson, and B. Worm. 2011. Creation of a gilded trap by the high economic value of the Maine lobster fishery. Conservation Biology 25:904-912. http://dx.doi.org/10.1111/j.1523-1739.2011.01717.x

Taleb, N. N. 2007. The black swan: the impact of the highly improbable. Random House, New York, New York, USA.

Uzzi, B., S. Mukherjee, M. Stringer, and B. Jones. 2013. Atypical combinations and scientific impact. Science 342:468-472. http:// dx.doi.org/10.1126/science.1240474

Van Eenwyk, J. R. 1997. Archetypes \& strange attractors: the chaotic world of symbols. Studies in Jungian Psychology By Jungian Analysts:75. Inner City Books, Toronto, Ontario, Canada.

Whitfield, J. 2008. An indifference to boundaries. Nature 451:872-873. http://dx.doi.org/10.1038/451872a

Wilson, E. O. 1998. Consilience: the unity of knowledge. Alfred A. Knopf, Inc., New York, New York, USA. 